\title{
Contaminación y epigenética: ¿nuestras expe- riencias afectan la salud de nuestros hijos?
}

\author{
Miguel Chin-Chan \\ María Guadalupe Maldonado-Velázquez
}

\section{Resumen}

La expresión de nuestros genes está regulada por etiquetas químicas adheridas al ADN que indican cuándo deben ser prendidos o apagados. Cualquier alteración en este patrón de etiquetas, especialmente durante etapas tempranas de la vida como el embarazo o la vida neonatal, puede afectar la expresión génica y producir efectos indeseados inmediatos o incluso muchas décadas después. Nuestras experiencias como el estilo de vida, la dieta y la contaminación pueden modificar el patrón de etiquetas químicas, y lo más alarmante es que algunos estudios sugieren que los efectos nocivos pueden heredarse de generación en generación. Así, es preciso preguntarnos si nuestras experiencias como los alimentos que comemos, el estilo de vida que llevamos y el ambiente en que vivimos afectarán la salud de nuestros hijos.

Palabras clave: epigenética, contaminación, transgeneracional, herencia, genética.

\section{Pollution and epigenetics: can our experiences affect THE HEALTH OF OUR CHILDREN?}

\begin{abstract}
Our gene expression is regulated by chemical tags attached to DNA which indicates when genes should be switched on or off. Any alterations in the pattern of these chemical tags, especially during early life stages, such as pregnancy or neonatal life, can affect gene expression immediately or even decades later. Our experiences such as lifestyle, diet and pollution can modify the pattern of chemical marks and the most worrying thing is that the harmful effects can inherit across generations, according to some studies. Thus, it would be precise to wonder ourselves whether our experiences such as the food we eat, the kind of life style we have and the environment where we live will affect the health of our children.
\end{abstract}

Key words: epigenetics, pollution, transgenerational, inheritance, genetics. 
células y nuestro cuerpo funcionen adecuadamente. Sin embargo, el patrón de etiquetas químicas en nuestros genes puede ser modificado por las experiencias por las que pasamos a lo largo de nuestra vida como el estilo de vida, la dieta o los contaminantes ambientales.

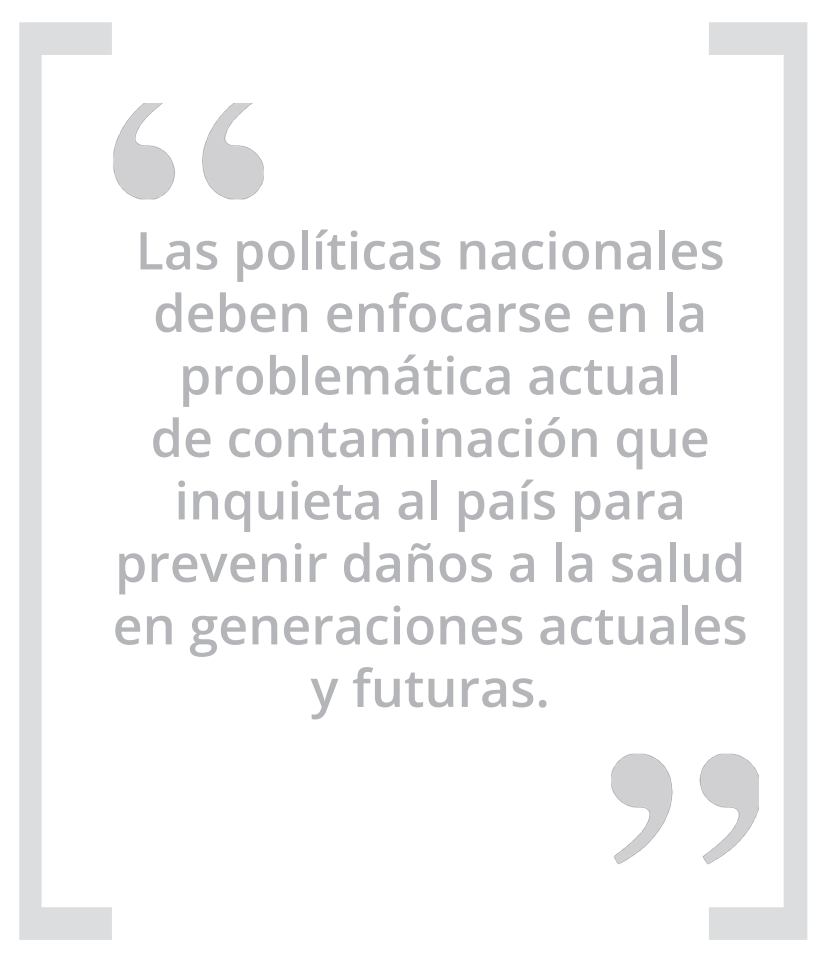

Es de especial importancia el tema de la contaminación pues representa un problema mundial que afecta la salud de los humanos y el medio ambiente. Cada día aumenta el número de estudios que relacionan la exposición a sustancias tóxicas con enfermedades crónico-degenerativas. La exposición a estas sustancias es especialmente peligroso en etapas susceptibles de la vida como durante el embarazo, la vida neonatal o la niñez, pues es en estas etapas cuando el establecimiento de marcas epigenéticas ocurre de manera activa. La perturbación de este fino proceso puede concluir en una lectura génica errónea, llevando a la activación o inhibición equivocada de los genes, y eventualmente conduciendo al desarrollo de enfermedades. La mayoría de las veces las consecuencias de estas alteraciones moleculares no aparecen de manera inmediata sino que toman años para manifestarse. Es preocupante que la alteración del patrón de etiquetas epigenéticas pueda ser heredada de generación en generación, sugiriendo la posibilidad que los efectos nocivos de la contaminación puedan ser transferidos a nuestros hijos y nietos a pesar de que ellos no estén expuestos.

\section{Gemelos idénticos y epigenética}

Para entender el concepto de epigenética pensemos en gemelos idénticos como los de la Figura 1. Ahora bien, asumamos que durante su infancia uno de ellos se muda a una gran ciudad con altos niveles de contaminación y el otro permanece en su pequeña ciudad natal. Con el tiempo, el gemelo de la pequeña ciudad se convierte en empleado de medio tiempo, invirtiendo su tiempo libre en la lectura y atletismo, además procura tener una alimentación balanceada y saludable; en contraste, el gemelo de la gran ciudad es gerente de una empresa importante, trabaja bajo estrés y presión todo el tiempo, tiene un estilo de vida

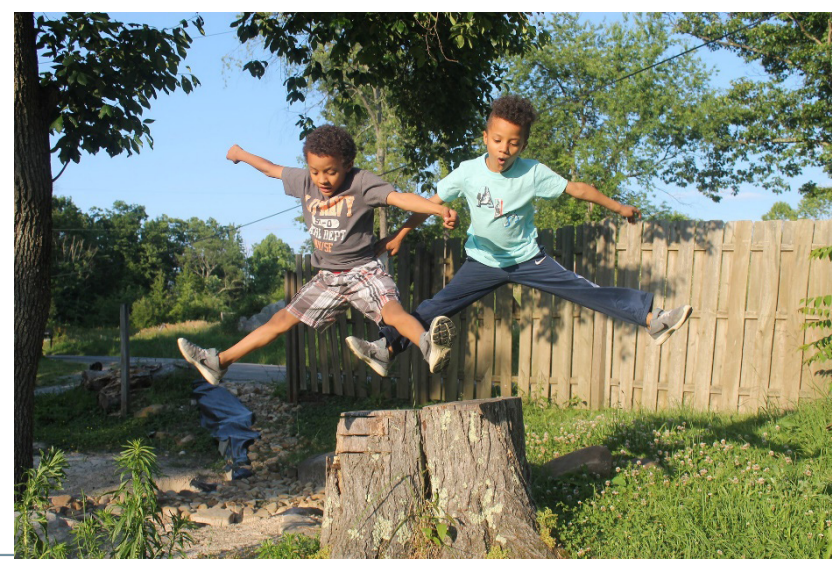


sedentario y su alimentación se basa en comida rápida y gaseosas. Tras el paso de los años el gemelo de la gran ciudad desarrolla obesidad y diabetes, mientras que el otro luce delgado y más joven.

Ahora reflexionemos un poco y pensemos: ¿a qué se deben estas diferencias entre los gemelos? Los dos poseen información genética idéntica porque proceden del mismo óvulo fertilizado (son homocigotos), por lo tanto, es poco probable que se haya dado un factor genético en el desarrollo de la obesidad y diabetes. Este panorama sugiere que las experiencias individuales (ambiente, estilo de vida y alimentación) influyen en gran medida en los fenotipos (delgado vs obeso) adquiridos. Gracias a que cada vez entendemos más sobre los mecanismos que regulan la expresión génica, se puede inferir que las diferencias entre los gemelos de este ejemplo se deben a cambios en la expresión de los genes como consecuencia de los ambientes particulares en los que se desarroIlaron. Estás influencias ambientales cambian el patrón de marcas epigenéticas en el ADN (puedes ver el video The epigenetics of identical twins que edita la Universidad de Utha).

Figura 1.

Epigenética: impacto del ambiente en la adquisición del fenotipo. Los gemelos idénticos a pesar de tener información genética similar desarrollan fenotipos distintos al crecer en ambientes diferentes.

\section{Gemelos idénticos}

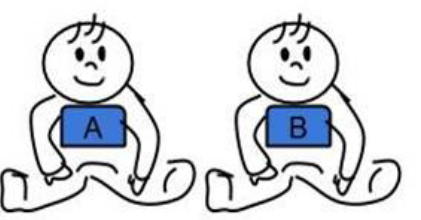

Influencias ambientales:

Deporte

Dieta saludable Ciudad baja contaminación
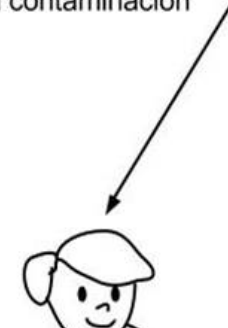

Patrones epigenéticos distintos

Diferentes influen
ambientales

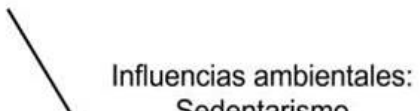

Sedentarismo

Dieta rica en grasas

Ciudad contaminada
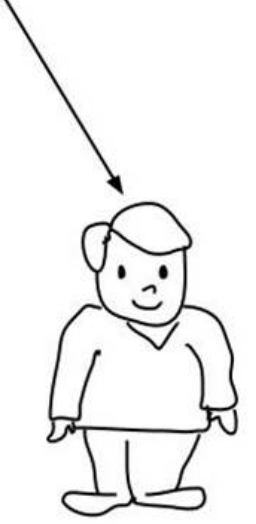
1. Metilación se refiere a la

"Reacción química por la cual una molécula pequeña que se llama grupo metilo se agrega a otras moléculas. La

metilación de las proteínas o los ácidos nucleicos puede afectar la forma en que estos actúan en el cuerpo" (Instituto Nacional del Cáncer).

2. Acetilación: "Reacción química en la que una molécula pequeña que se llama grupo acetil se añade a otras moléculas. La acetilación de proteínas puede afectar el modo en que estas actúan en el cuerpo" (Instituto Nacional del Cáncer).

3. Fosforilación: "Proceso mediante el cual se agrega un grupo de fosfato a una molécula, como un azúcar o una proteína" (Instituto Nacional del Cáncer).

Figura 2. Regulación epigenetica de las expresiones génicas. El ADN es una biomolécula en la que se encuentran los genes los cuales dan origen al ARN mensajero para la síntesis de proteinas que participan en la función celular. La expresión génica está influenciada por marcas epigenéticas (como metilación del ADN, metilación, acetilación y fosforilación de histona) o por otros mecanismos como los micro ARNs. Factores estresantes como la dieta, estilo de vida o contaminación

pueden cambiar el patrón de marcas epigenéticas modificando la expresión génica.

\section{Las marcas y modificaciones epigenéticas}

La definición de epigenética se refiere a cambios heredables en el ADN que no afectan la secuencia de los genes pero que sí alteran su lectura (Skinner et al., 2010) (a este respecto, sugerimos ver el video The Epigenome at a Glance). Es decir, dichos cambios o modificaciones epigenéticas se refieren a etiquetas químicas adheridas al ADN o a las histonas (proteínas en las cuales se 'empaca' el ADN) que pueden alterar la expresión de los genes.

Las marcas epigenéticas más estudiadas son la metilación' del ADN, la metilación, acetilación ${ }^{2}$ y fosforilación ${ }^{3}$ de histonas, y los micro ácidos ribonucléicos (ARNs), como se ilustra en la figura 2.

Se sabe que en general la metilación del ADN (adición de un grupo metilo - $\mathrm{CH} 3$, al ADN) tiene como consecuencia el apagado de la expresión génica por mecanismos moleculares que impiden la transcripción (conversión del ADN a ARN) (Ho et al., 2012). La modificación de histonas básicamente consiste en etiquetas químicas como la metilación (-CH3), acetilación (adición del grupo acetilo, - $\mathrm{COCH} 3$ ) y fosforilación (adición del fósforo, P) que le indican a estas proteínas si deben "enrollar" o "desenrollar "el ADN, facilitando o reduciendo la disponibilidad en la lectura génica (Ho et al., 2012) (ver Figura 2). Además, dentro de las marcas epigenéticas, que son propiamente mecanismos de regulación génica, se encuentran los micro ARNs, que son moléculas pequeñas de ARN que apagan la expresión génica al bloquear la traducción (conversión de ARN a proteína).

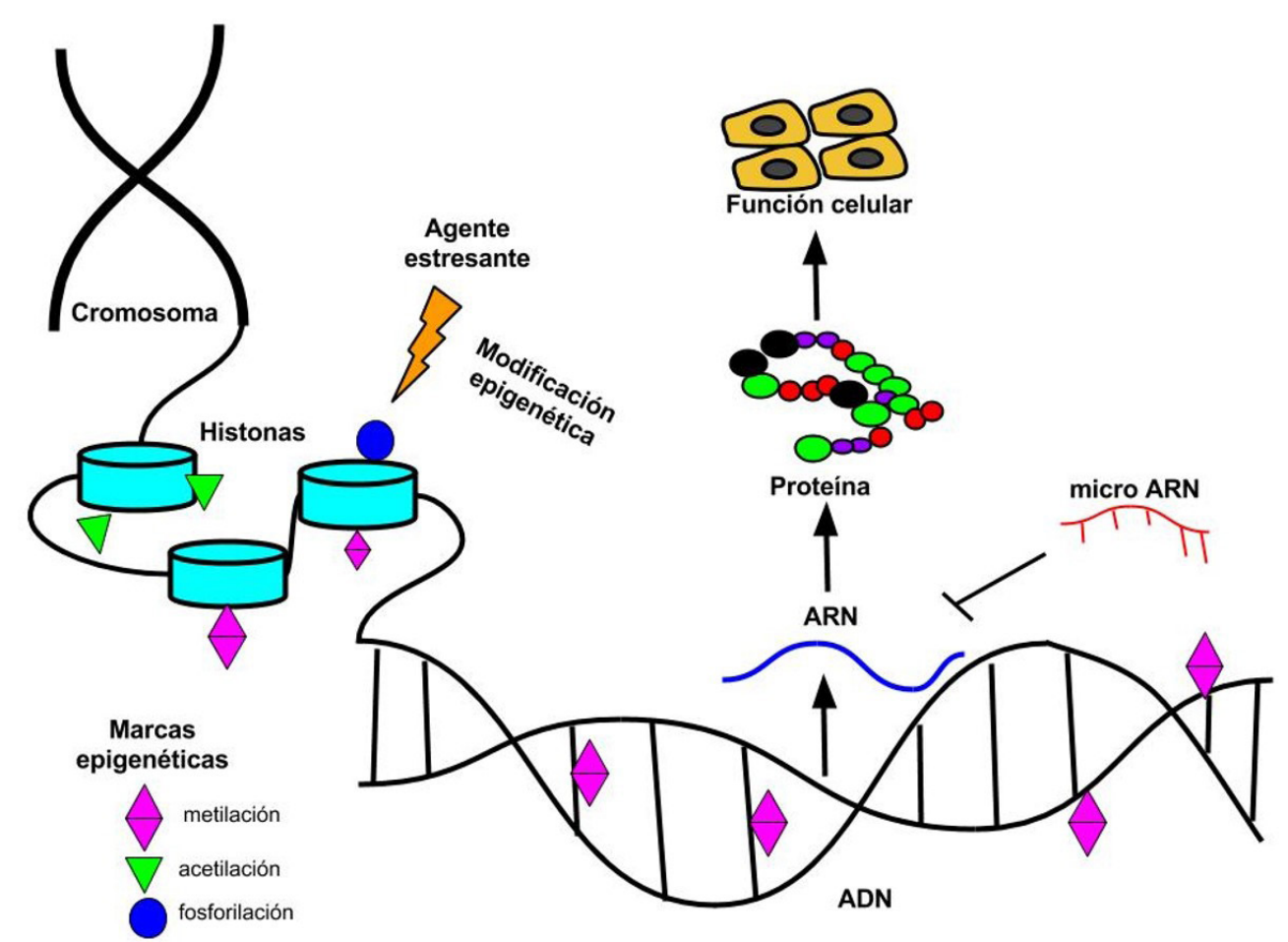




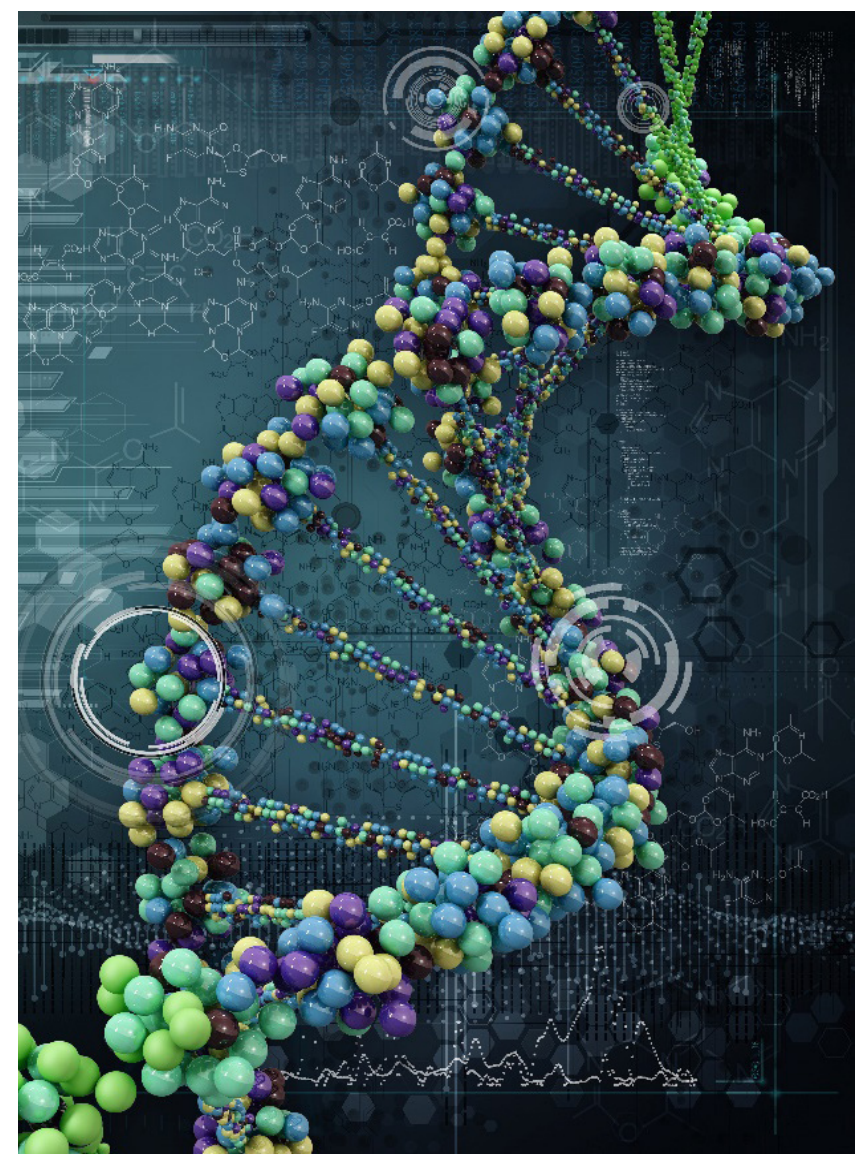

El patrón de marcas epigenéticas en el genoma de cada individuo puede ser alterado por el ambiente intracelular (dentro de la célula), intercelular (entre las células) o por agentes externos. La adición de estas etiquetas al ADN hace que unos genes se enciendan y otros se apaguen, y confiere una gran flexibilidad en la expresión del genoma. La sumatoria de todas estas marcas químicas (metilación, acetilación, etcétera) en el genoma se conoce como epigenoma, y tiene amplias implicaciones en la salud y la enfermedad. Por ejemplo, durante el desarrollo embrionario el ADN es etiquetado con marcas epigenéticas que regulan un fino y coordinado encendido y apagado de los genes, indicando a las células embrionarias cuándo y en qué lugar deben convertirse en una célula de riñón, hígado, cerebro o de otro tipo (Kiefer, 2007). En contraste, en enfermedades como el cáncer también se ha observado alteraciones del epigenoma promoviendo un crecimiento descontrolado de células aberrantes que llevan a la formación de tumores (University of Utha).

\section{Enfermedades de la edad adulta asociadas a un origen fetal}

Barker y sus colegas plantearon que hay "enfermedades de la edad adulta asociadas a un origen fetal" (en Lucas et al., 1999). Basándose en un estudio, observaron que una escasa nutrición durante la vida intrauterina (antes de nacer) tiene como resultado neonatos con bajo peso, los cuales tienen mayor riesgo de desarrollar diabetes en la vida adulta. Esto sugiere que condiciones adversas (desnutrición, infecciones, exposición a contaminantes) durante etapas tempranas de la vida puede predisponer el desarrollo de enfermedades en la vida adulta.

Pero, ¿qué y cómo se producen estos efectos tardíos? Dada la alta frecuencia de la mayoría de las enfermedades de la edad adulta (hipertensión, diabetes, cardiovasculares, etcétera), se ha sugerido que la probabilidad que sean 
causadas por mutaciones genéticas es realmente escasa, pues la frecuencia con que aparecen mutaciones en el ADN es de alrededor de 0.01\% (Skinner, 2008). Aunque los mecanismos detrás del desarrollo de estas enfermedades no se conocen por completo, se considera que la epigenética juega un papel importante.

En etapas específicas del desarrollo embrionario, por ejemplo después de la fertilización, ocurre un proceso conocido como reprogramación genómica en la que las marcas epigenéticas del ADN son borradas y nuevas marcas son impresas para garantizar un desarrollo correcto del organismo (Kaneda, 2011). Estas marcas epigenéticas, le permiten a la célula 'recordar' qué es lo que sus genes deben hacer posteriormente, sirviendo como un mecanismo de memoria molecular. El proceso de borrado e impresión de las marcas epigenéticas es crítico porque cualquier perturbación podría conducir a fenotipos anormales en la vida adulta (Skinner, 2011). Por ejemplo, un estudio mostró que monos recién nacidos intoxicados durante 13 meses (infantes) con dosis de plomo (un metal pesado) no presentaron manifestaciones clínicas en los años siguientes; sin embargo, a la edad de 23 años (ancianos) el cerebro de estos animales contenía agregados de proteínas como los que se observa en los pacientes con Alzheimer, mostrando que los efectos dañinos del plomo aparecieron décadas después de la exposición (Wu et al., 2008). Así, de acuerdo con la hipótesis de Barker, muchas de las alteraciones en nuestra salud actual pueden ser consecuencia de las condiciones por las que pasamos durante la vida temprana.

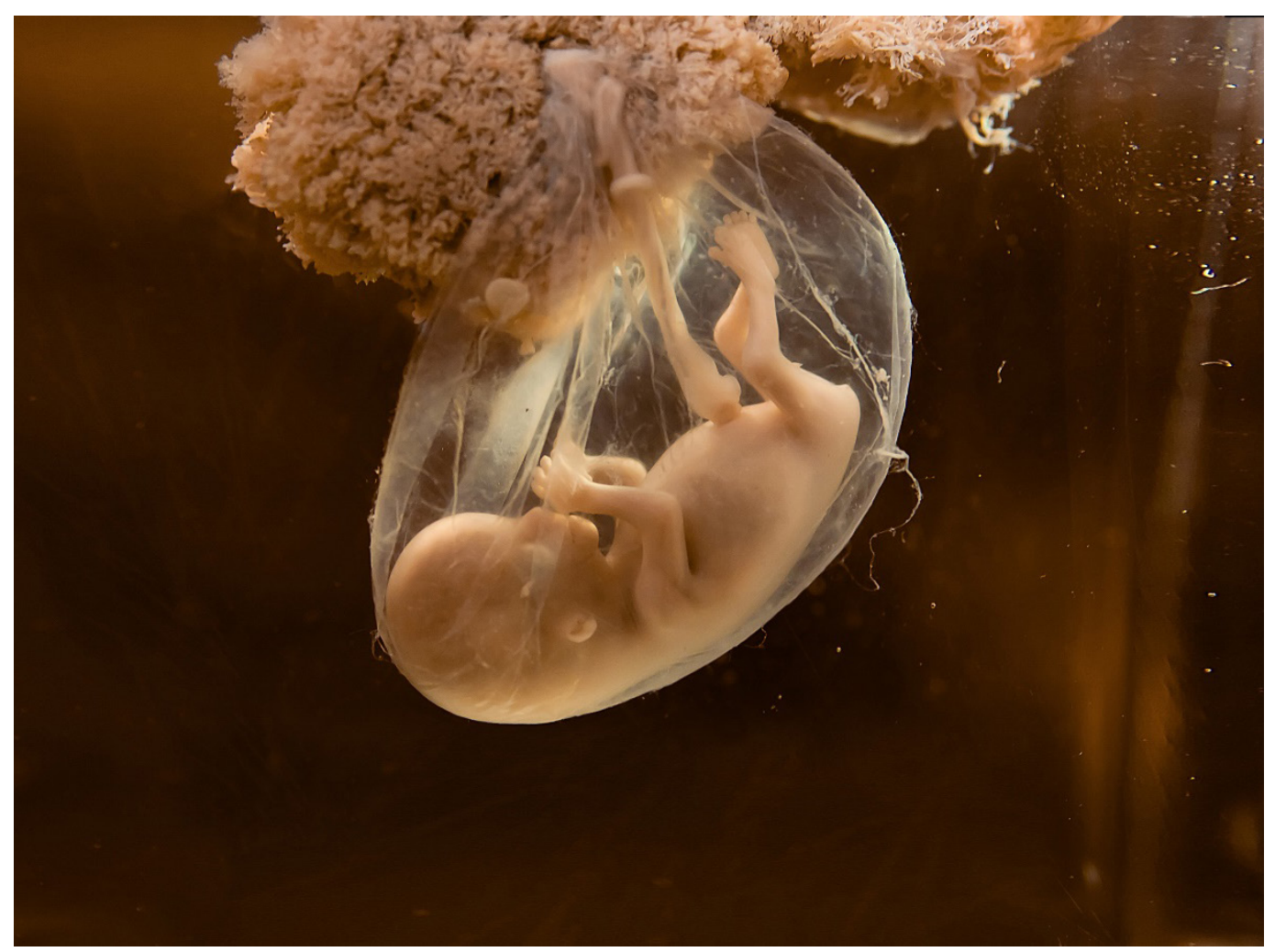




\section{Herencia multi y transgeneracional ¿Hay alguna diferencia?}

Durante nuestros años de secundaria aprendemos que la herencia consiste exclusivamente en la trasmisión de genes de padres a hijos; es decir, la herencia mendeliana se refiere a transmisión de genes. Sin embargo, ahora este término está sufriendo modificaciones, porque la herencia epigenética establece que no sólo los genes, sino también las etiquetas químicas contenidas en genes específicos pueden ser transferidos generacionalmente (Skinner, 2011). Si las marcas epigenéticas pueden heredarse, entonces sería lógico pensar que los fenotipos anormales producidos por factores externos pueden también heredarse de modo multi y transgeneracional. Ahora bien ¿Cuál es la diferencia entre estos términos que suenan bastante similar? Para comprenderlo, asumamos que una mujer embarazada habita en un ambiente contaminado cerca de una zona industrial (como en la figura 3). La exposición de esta mujer embarazada (generación 0, F0) a las sustancias tóxicas facilita que el embrión (futuro hijo, generación F1) y las células germinales del embrión (futuro nieto, generación F2) también estén en contacto directo con la contaminación.

En epigenética se ha establecido que cuando los fenotipos adquiridos (por ejemplo, enfermedad) por los descendientes se dan mediante exposición directa es un efecto multigeneracional (Skinner, 2008). En otras palabras, cualquier alteración observada en los hijos (F1) y nietos (F2) de la madre embarazada (F0) se considera efecto multigeneracional; mientras que los efectos observados en los bisnietos (F3) son de tipo transgeneracional puesto que esta generación no estuvo expuesta directamente a los compuesto tóxicos (véase la Figura 3).

Figura 3.

Efectos multi y transgeneracionales por exposición a contaminantes ambientales. Una mujer embarazada representa a la generación F0, el embrión a la F1 y las células germinales de este último a la generación F2. En este caso los efectos producidos por la contaminación ambiental en las generaciones F0-F2 son de tipo multigeneracional y los efectos en la generación F3

son transgeneracionales.

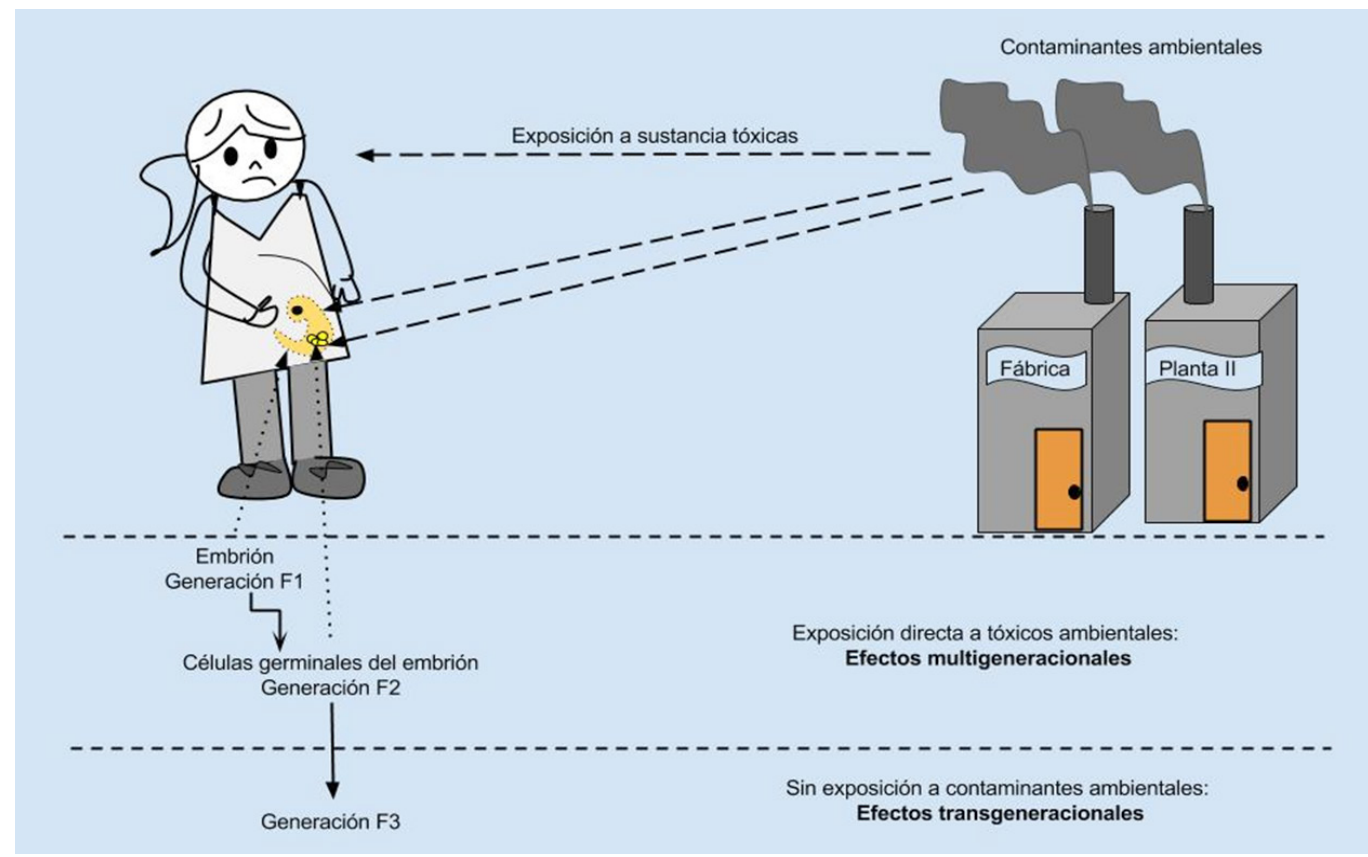




\section{Efectos transgeneracionales causados por sustancias tóxicas}

Actualmente la contaminación ha tomado un papel relevante en el origen de las enfermedades, de acuerdo con el último estudio realizado por la Organización Mundial de la Salud al menos un cuarto de las enfermedades están relacionadas con factores ambientales (OMS, 2006). Sin embargo, no siempre somos conscientes de los efectos de la contaminación porque en la mayoría de los casos no observamos efectos inmediatos, en cambio pueden transcurrir años para manifestarse. Además, con el creciente campo de la epigenética ambiental y transgeneracional es razonable pensar que algunos de los efectos en nuestra salud podrían ser consecuencia de exposiciones pasadas a ambientes estresantes o, incluso, a experiencias de nuestros padres o abuelos.

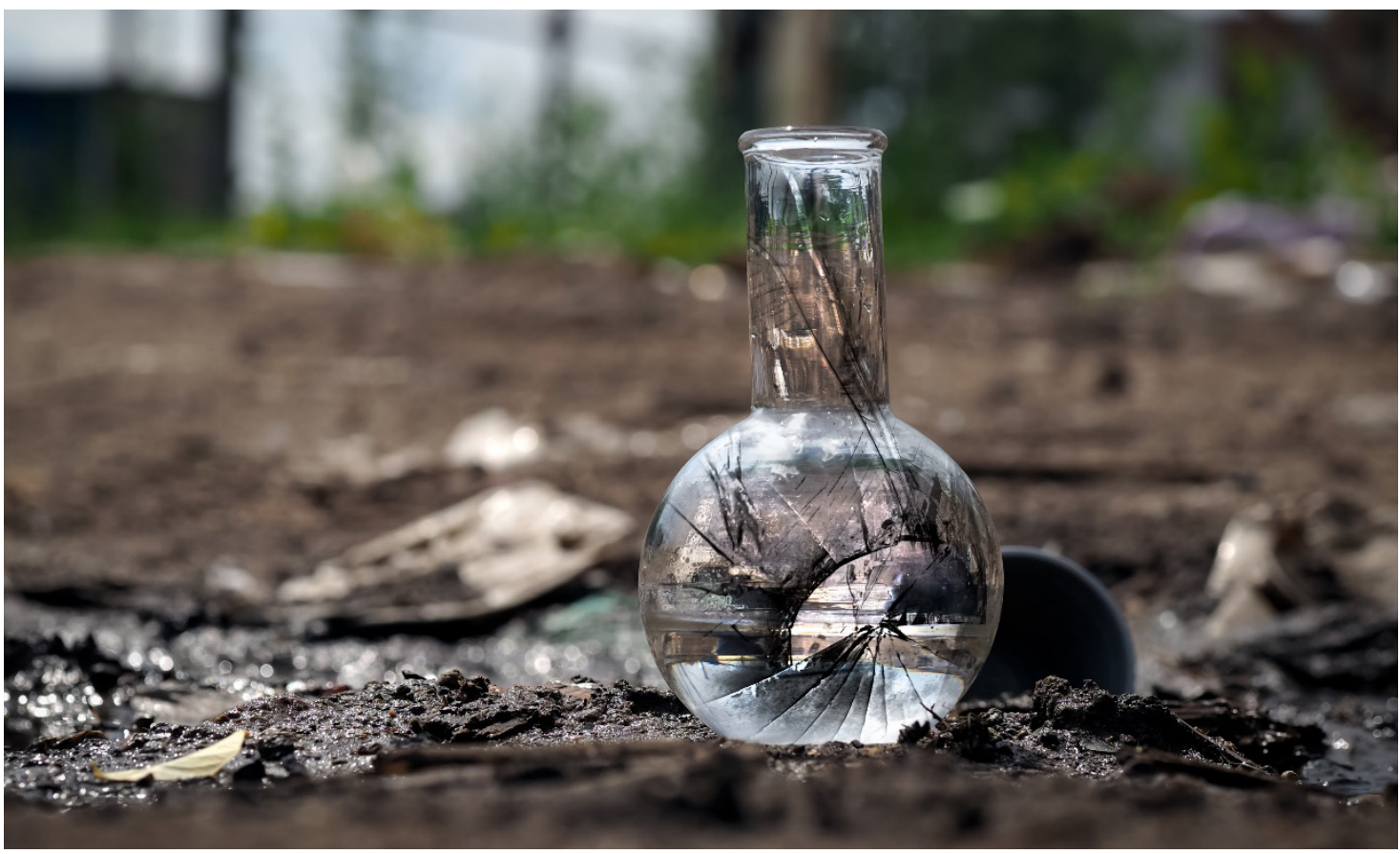

Uno de los primeros estudios que determinó los efectos transgeneracionales producidos por exposición a sustancias tóxicas fue un estudio en el que se expusieron ratas gestantes (F0) a la vinclozolina, un fungicida para la preservación de frutas, observando efectos colaterales en la fertilidad de las generaciones siguientes (F2, F3 y F4) de ratas macho adultas (Anway et al., 2005), los cuales fueron causados por alteraciones epigenéticas (Anway y Skinner, 2008).

Un número creciente de estudios ha mostrado que los disruptores endócrinos (compuestos que mimetizan o antagonizan la acción de las hormonas) como el 2,3,7,8-tetrahidroclorobenceno dioxina (TCDD), el diclodifeniltricloroetano (DTT) y el bisfenol A (BPA), por citar algunos, producen efectos transgeneracionales en 
animales de experimentación (Skinner, 2014). Es muy interesante el hecho que la exposición al insecticida DDT, el cual se usó por mucho tiempo en México para el control de la malaria, es capaz de producir obesidad en la descendencia de ratas expuestas (Skinner et al., 2013). Esto sugiere, aunque hacen falta estudios confirmatorios en humanos, que las exposiciones pasadas a DTT podrían estar contribuyendo con el problema actual de obesidad en México. En este sentido, un creciente número de compuestos químicos llamados obesógenos se han sumado a la lista de sustancias que exacerban la obesidad en animales de experimentación y que se sugiere puede ser trasmitida entre generaciones (Kelishadi et al., 2013). Por supuesto, el problema de obesidad también es influenciado por factores dietéticos como la comida rica en grasas.

El BPA, un componente del plástico que se encuentra en muchos recipientes de uso doméstico, también se ha implicado en alteraciones reproductivas y problemas de conducta social. Por ejemplo, en un estudio científico se encontró que la exposición de ratones gestantes a BPA -concentraciones similares a las encontradas en humanos-, produjo alteraciones en la capacidad de reconocimiento social, no sólo en los ratones expuestos intrauterinamente sino también en su descendencia (Wolstenholme et al., 2013).

\section{¿Cuál es el futuro de nuestros hijos?}

Estudios epidemiológicos, como el que se dio a raíz de la hambruna holandesa de 1944, dejan claro que las alteraciones fenotípicas causadas por un ambiente estresante durante etapas críticas del desarrollo pueden ser transmitidas entre generaciones. Durante este lamentable suceso un gran número de personas estuvieron sometidas a un estado de desnutrición severa, como consecuencia los hijos y nietos de madres gestantes desarrollaron enfermedades cardiovasculares y obesidad en la vida adulta (Veenendaal et al., 2013).

Así mismo, la exposición a dietilestilbestrol (DES), un fármaco estrogénico usado de 1940 a 1970 para evitar el aborto espontáneo, produjo daños reproductivos en personas expuestas y su descendencia (Reed y Fenton, 2013), indicando que situaciones adversas en etapas críticas de la vida pueden causar alteraciones multigeneracionales. No obstante, la transmisión a nivel transgeneracional todavía no ha sido demostrada en humanos.

Los escasos datos que sustenten los efectos transgeneracionales en humanos se debe a que estos estudios requieren de muchos años de evaluación. No obstante, los estudios en animales son contundentes (Skinner et al., 2010; Skinner, 2011; Kelishadi et al., 2013) y arrojan datos particularmente alarmantes para países en vías de desarrollo como México, donde no existen suficientes programas de regulación ambiental. Esto ha favorecido que algunas poblaciones se encuentren expuestas crónicamente a sustancias tóxicas, como las 
localidades mineras, comunidades agrícolas y las grandes ciudades con niveles altos de contaminación del aire.

Las políticas nacionales deben enfocarse en la problemática actual de contaminación que inquieta al país para prevenir daños a la salud en generaciones actuales y futuras. Es necesario establecer programas regulatorios para el uso de los compuestos químicos, como el BPA empleado en la manufactura de plásticos con los que se fabrican recipientes de uso doméstico como los biberones, pues en los recién nacidos ocurre regulación epigenética activa, representando una ventana de susceptibilidad. La regulación actual del DDT debe ser revisada, pues en comunidades rurales continúa usándose clandestinamente debido a su bajo costo y efectividad como insecticida. Es recomendable también establecer programas de concientización enfocados a agricultores y sus familias, quienes poseen equipos de protección limitados o nulos.

La herencia transgeneracional sugiere que nuestras acciones impactan la salud de nuestros descendientes, como probablemente también nuestra salud actual sea un reflejo, al menos parcial, de las acciones de nuestros padres o abuelos. Sin embargo, la epigenética es maleable y nos da la oportunidad de regular la expresión de nuestros genes a través de nuestras acciones, por lo que una dieta saludable, el ejercicio y evitar la exposición a sustancias tóxicas -sobre todo en etapas críticas de la vida como el embarazo-, ofrece grandes beneficios a nuestra salud y la de nuestros descendientes.

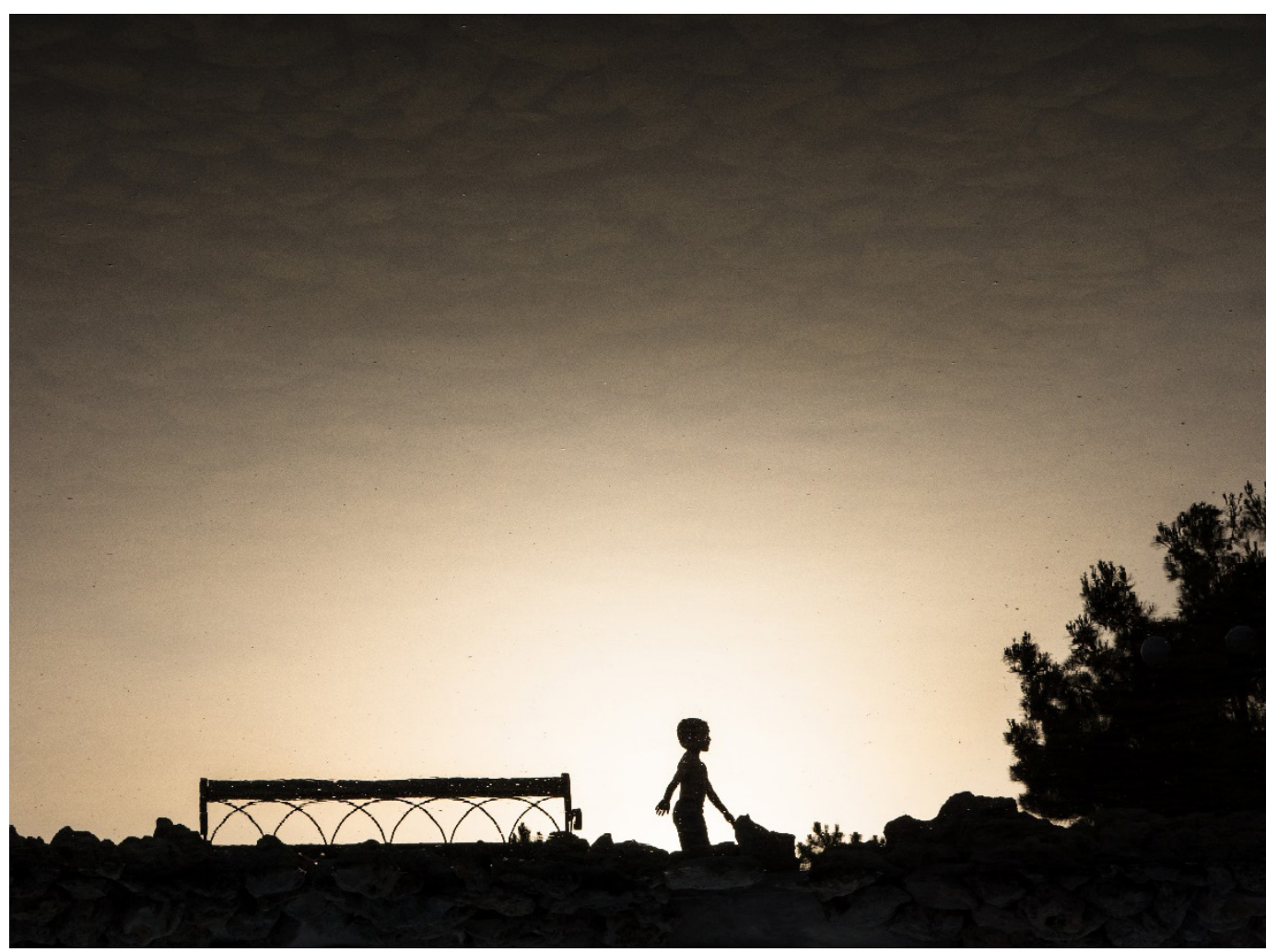




\section{Conclusión}

La epigenética juega un papel importante en el encendido y apagado de los genes; sin embargo, los agentes externos como la contaminación ambiental pueden modificar el epigenoma alterando el patrón de expresión génica. Estas alteraciones pueden producir efectos dañinos en la salud en la vida adulta tardía; o peor aún, podrían ser transmitidas a generaciones futuras. Aunque aún hacen falta más estudios confirmatorios en humanos, la epigenética da cuenta de la responsabilidad que tenemos sobre la salud de nuestros hijos y nietos.

\section{Referencias}

* Anway, M. D., A. S. Cupp, M. Uzumcu y M. K. Skinner (2005). Epigenetic transgenerational actions of endocrine disruptors and male fertility. Science. 308:1466-1469. DOI: https://doi.org/10.1126/science.1108190

* Anway, M. D. y M. K. Skinner (2008). Epigenetic programming of the germ line: effects of endocrine disruptors on the development of transgenerational disease. Reprod Biomed Online. 16: 23-25. https://doi.org/10.1016/S1472-6483(10)60553-6

* Ho, S. M., A. Johnson, P. Tarapore, V. Janakiram, X. Zhang y Y. K. Leung (2012). Environmental epigenetics and its implication on disease risk and health outcomes. ILARJ. 53: 289-305. DOI: https://doi.org/10.1093/ilar.53.3-4.289

* Kaneda, M. (2011). Genomic imprinting in mammals-epigenetic parental memories. Differentiation. 82: 51-56. DOl: https://doi.org/10.1016/j.diff.2011.05.004

* Kelishadi, R., P. Poursafa y F. Jamshidi (2013). Role of environmental chemicals in obesity: a systematic review on the current evidence. J Environ Public Health. 2013: 896789. DOI: http://dx.doi.org/10.1155/2013/896789.

* Kiefer, J. C. (2007). Epigenetics in development. Developmental Dynamics. 236: 1144-1156. DOl: https://doi.org/10.1002/dvdy.21094.

- Lucas, A., M. S. Fewtrelly T.J. Cole (1999). Fetal origins of adult disease-the hypothesis revisited. BMJ. 319: 245-249. DOI: https://doi.org/10.1136/bmj.319.7204.245.

* OMS (2006). La exposición a riesgos ambientales provoca casi una cuarta parte de las enfermedades. Centro de prensa. http://www.who.int/mediacentre/news/ releases/2006/pr32/es/.

Reed, C. E. y S. E. Fenton (2013). Exposure to diethylstilbestrol during sensitive life stages: a legacy of heritable health effects. Birth Defects Res C. 99: 134-146. DOI: http://doi.org/10.1002/bdrc.21035.

- Skinner, M. K. (2008). What is an epigenetic transgenerational phenotype? F3 or F2. Reproductive Toxicology. 25: 2-6. DOI: http://doi.org/10.1016/j.reprotox.2007.09.00.

* Skinner, M. K. (2011). Environmental epigenetic transgenerational inheritance 
and somatic epigenetic mitotic stability. Epigenetics. 6(7), 838-842. DOI: http://doi. org/10.4161/epi.6.7.16537.

* Skinner, M. K. (2014). Endocrine disruptor induction of epigenetic transgenerational inheritance of disease. Mol Cell Endocrinol. 398: 4-12. DOI: https://doi. org/10.1016/j.mce.2014.07.019.

* Skinner, M. K., M. Manikkam y C. Guerrero-Bosagna (2010). Epigenetic transgenerational actions of environmental factors in disease etiology. Trends Endocrinol Metab. 21: 214-222. DOI: https://doi.org/10.1016/j.mce.2014.07.019.

* Skinner, M. K., M. Manikkam, R. Tracey, C. Guerrero-Bosagna, M. Haque y E. E. Nilsson (2013). Ancestral dichlorodiphenyltrichloroethane (DDT) exposure promotesepigenetic transgenerational inheritance of obesity. BMC Medicine. 11: 228. DOI: https://doi.org/10.1186/1741-7015-11-228.

* University of Utha (s.f) Insights From Identical Twins. Learn genetics. Genetic Science Learning Center. University of Utha. Recuperado de http://learn.genetics.utah.edu/ content/epigenetics/twins/.

* Veenendaal, M. V., R. C. Painter, S. R. de Rooij, P. M. Bossuyt, J. A. van der Post, P. D. Gluckman, M. A. Hanson y T. J. Roseboom (2013). Transgenerational effects of prenatal exposure to the 1944-45 Dutch famine. BJOG 120: 548-553. DOI: https:// doi.org/10.1111/1471-0528.12136.

Wolstenholme, J. T., J. A. Goldsby y E. F. Rissman (2013). Transgenerational effects of prenatal bisphenol A on social recognition. Hormones and Behavior 64: 833839. DOI: https://doi.org/10.1016/j.yhbeh.2013.09.007.

* Wu, J., M. R. Basha, B. Brock, D. P. Cox, F. Cardozo-Pelaez, C. A. McPherson, J. Harry, D. C. Rice, B. Maloney, D. Chen, D. K. Lahiri y N. H. Zawia (2008). Alzheimer's disease (AD)-like pathology in aged monkeys after infantile exposure to environmental metal lead (Pb): evidence for a developmental origin and environmental link for AD. Journal of Neuroscience. 28:3-9. DOI: https://doi.org/10.1523/JNEUROSCl.4405-07.2008.

\section{Cómo citar este artículo}

* Chin Chan, Miguel y Maldonado Velázquez, María Guadalupe (2018). Contaminación y epigenética: ¿nuestras experiencias afectan la salud de nuestros hijos? Revista Digital Universitaria (RDU). Vol. 19, núm. 1 enero-febrero. DOI: http://doi. org/10.22201/codeic.16076079e.2018.v19n1.a2. 